\title{
Antibiotics and near-patient testing: Differences in habits between physicians completing or discontinuing a medical audit
}

\author{
Katarina Hedin ${ }^{1,2^{*}}$, Annika Brorsson ${ }^{1}$, Sigvard Mölstad ${ }^{1}$, Eva Lena Strandberg ${ }^{1,3}$ \\ ${ }^{1}$ Department of Clinical Sciences, Malmö, General Practice/Family Medicine, Lund University, Lund, Sweden \\ ${ }^{2}$ Unit for Research and Development Kronoberg County Council, Växjö, Sweden; \\ *Corresponding Author: katarina.hedin@ltkronoberg.se \\ ${ }^{3}$ Blekinge Centre of Competence Blekinge County Council, Karlskrona, Sweden
}

Received 11 November 2013; revised 15 December 2013; accepted 5 January 2014

Copyright (c) 2014 Katarina Hedin et al. This is an open access article distributed under the Creative Commons Attribution License, which permits unrestricted use, distribution, and reproduction in any medium, provided the original work is properly cited. In accordance of the Creative Commons Attribution License all Copyrights (C) 2014 are reserved for SCIRP and the owner of the intellectual property Katarina Hedin et al. All Copyright (C 2014 are guarded by law and by SCIRP as a guardian.

\section{ABSTRACT}

Background and Aim: Respiratory tract infection (RTI) is a common reason for consulting primary health care. Antibiotic prescribing for RTIs varies among physicians indicating that national guidelines are not always adhered to. The aim was to study if antibiotic prescribing and use of near-patient tests were different among physicians who complete an audit registration and those who discontinue their participation. Method: A prospective cohort study where physicians participated in an APO (Audit Project Odense) process, making an audit registration for every appointment with a patient who had a respiratory tract infection during 4 weeks in 2008 and 4 weeks in 2009. Between the registrations, a limited educationally oriented intervention was made. 18 Primary Health Care Centres located in three counties in southern of Sweden with 77 primary health care physicians participated. When comparing proportions the Chisquare test was used. Mann Whitney U-test was used when comparing independent groups and Wilcoxon's signed-rank test was used when comparing dependent groups. Results: Of the 77 physicians, 38 participated only at baseline (group 1) and 39 participated in both registrations (group 2). The overall use of CRP nearpatient tests was $37 \%$ in group 1 and $28 \%$ in group 2 (Chi-square $p<0.001$ ), and the overall use of Strep-A near-patient tests was $31 \%$ and $20 \%$, respectively (Chi-square $p<0.001$ ). When the Strep-A near-patient test was negative in pharyngitis/tonsillitis, antibiotics were prescribed to $45 \%$ in group 1 and to $12 \%$ by group 2 (Chisquare 0.003). Conclusion: In conclusion, this study showed that physicians, who were more inclined to complete audit participation, used near-patient tests and prescribed antibiotics more correctly, according to the national guidelines for respiratory tract infections, than physicians who discontinued the participation. To achieve a rational use of antibiotics, near-patient tests and prescription of antibiotics must be used according to guidelines.

\section{KEYWORDS}

Respiratory Tract Infections; Primary Health Care; Near-Patient Test; Antibiotic Prescription; Audit Registration

\section{INTRODUCTION}

Respiratory tract infection (RTI) is one of the most common reasons for consulting primary health care (PHC) in the Nordic countries [1,2]. In Sweden, approximately $18 \%$ of all physician appointments in $\mathrm{PHC}$ are attributable to RTI [1], and of all patients seeking for RTI at a PHC Centre (PHCC), 49\% were prescribed antibiotics [3].

Sweden has national guidelines on how to manage RTIs [4-7]. In cases of sore throat only, patients with more than three Centor criteria should be tested with a rapid test for Streptococcus pyogenes (Strep-A) and treated with antibiotics if positive [8]. Near-patient StrepA tests show whether or not Streptococcus pyogenes (S.p) 
are present with more than 95\% specificity and 60\% - 96\% sensitivity, using culture as the gold standard [9]. C-reactive protein (CRP) is recommended in lower RTIs when pneumonia cannot be clinically excluded [10]. The high use of Strep-A and CRP in Sweden has been questioned [11].

Antibiotic resistance is increasing, and the higher the level of antibiotic use is, the higher the risk of resistance in society [12] and in individuals will be [13]. Antibiotic prescribing for RTIs varies among general practitioners (GPs) in different countries [14], different counties in Sweden [15], and among GPs at different PHCCs [16], as well as among individual GPs [17], indicating that guidelines are not always adhered to. We know that prescribing patterns also differ among GPs who agree or decline to participate in medical audit registrations such as an audit according to the Audit Project Odense (APO) method [18]. However, we have not found any studies focusing on management of common infections and investigating differences in antibiotic prescribing and use of near-patient tests among physicians who complete an audit registration and those who discontinue their participation.

The APO method was used in the EU project Heath Alliance for Prudent Prescribing, Yield and Use of Antimicrobial Drugs in the Treatment of Respiratory Tract Infections (Happy Audit) [19-21]. From this project we know that the discontinuation rate varies among countries and the highest discontinuation level was among the Swedish participators [19].

The main aim of this study was to study whether the initial use of near-patient tests and the antibiotic prescribing habits of physicians at PHCCs in Sweden differed among those who completed an audit registration and those who discontinued participation after baseline registration. The aim was also to study the use of nearpatient tests and antibiotic prescribing when the physician marked the diagnosis pharyngitis/tonsillitis. Another aim was to study if the use of near-patient tests and antibiotic prescribing by those who completed both audit registrations changed after a limited educationally oriented intervention.

\section{MATERIAL AND METHODS}

\subsection{The APO Method}

The audit registration was made according to the APO method. APO has been developed and successfully tested among different groups of GPs in the Nordic countries. It is carried out by the individual physician, who registers every appointment for a specific problem and notes action taken during the consultation [22-24]. The basic principle of the audit according to the APO method is a circle of elements including: first audit registration, individual feedback of the results from the registration, group discussion and follow-up activities (intervention), second registration and a final evaluation [25].

\subsection{Setting}

This study was a prospective cohort study which was part of the EU project Heath Alliance for Prudent Prescribing, Yield and Use of Antimicrobial Drugs in the Treatment of Respiratory Tract Infections (Happy Audit) [20,21]. In the Swedish part, a convenient sample of 18 PHCCs located in three counties in southern Sweden was chosen. The PHCCs were located in both rural and urban areas with approximately between 3000 and 10,000 listed patients. All physicians working at the PHCCs were invited to participate in the audit.

In Sweden, nurses often do the initial evaluation of the respiratory tract symptoms by phone, giving advice or recommending a consultation with a physician. No nurses were invited to take part in this audit.

\subsection{The Happy Audit Project}

During 4 weeks in January 2008 and 4 weeks in January 2009, the physicians were asked to register all appointments for RTIs. Each physician noted the age and sex of the patient, type of respiratory tract symptoms, and duration of symptoms. A diagnosis according to preset alternatives and the actions taken by the physician were also noted for each patient. Each PHCC received patient leaflets about RTIs to distribute to patients at appointments, and each physician received short guidelines about the Swedish recommendations for RTIs. All 77 invited physicians participated in the first audit registration in January 2008. Although the agreement was that all physicians would also take part in the second registration one year later, only 39 physicians completed the second registration. Thus there were two groups-group 1 , physicians who discontinued participation after the follow-up meeting and intervention, but before the second registration and group 2, physicians who participated in both audit registrations (Figure 1).

\subsection{Intervention}

After the first registration an educational intervention took place during the spring of 2008. The authors visited the physicians at each PHCC on one occasion or in some cases the physicians from more than one PHCC together to inform them and to have a dialogue about how to manage RTIs according to the Swedish guidelines [4-6,10]. At the meeting, each physician received a report including his own data and the overall results from the first registration. Thus the physicians were able to compare and discuss their own results at the meeting and decide on necessary changes in management according to national guidelines. We also arranged educational 


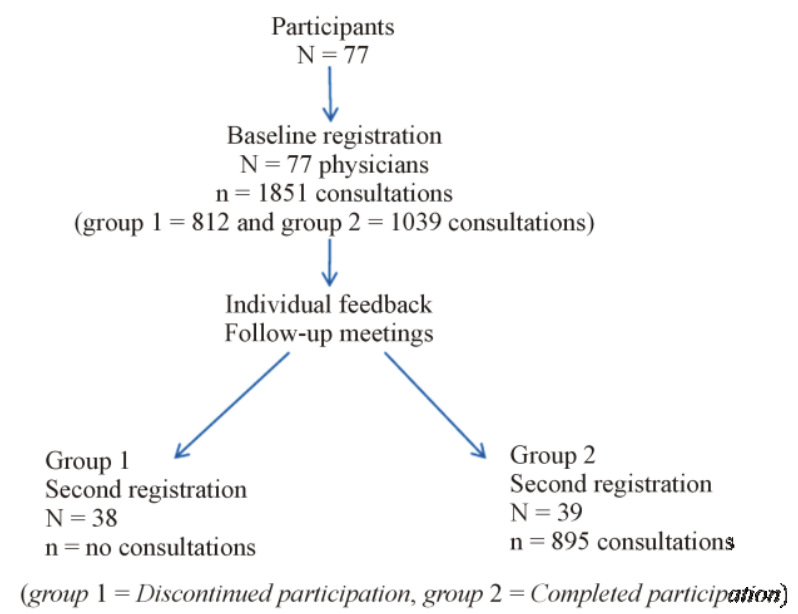

Figure 1. Participants flowchart.

oriented meetings with the presence of national and local specialists of the research field focusing on new evidence regarding resistance development and consequences for management of RTIs.

\subsection{Definitions}

The illness included in "diagnosis recommended for treatment with antibiotics" were acute tonsillitis with a positive Strep-A near-patient test, acute otitis media in children younger than two years of age, pneumonia, COPD (Chronic obstructive pulmonary disease) with the note "probably a bacterial infection" marked on the audit registration and the diagnosis of sinusitis with duration of symptoms for at least ten days.

\subsection{Statistical Methods}

In this study physician from the same Primary Health Care Centres (PHCC) could either belong to group 1, the discontinued participating group or to group 2, the complete participating group. Thus there was a mix of physicians in the PHCCs. Our data were analysed in two ways. First, all consultations were analysed together. Second we aggregated each physician's consultations, calculating a mean value for each doctor based on different numbers of visits for each physician before we made the analyses, since we wanted to take into account that the physicians registered different numbers of consultations.

When comparing the total use of near-patient tests and the total use of antibiotics, the Chi-square test was used independent data on group level. When comparing data from the independent groups-group 1 and group 2 and taking into account that the physicians registered different numbers of consultations, the Mann Whitney U-test was used. When comparing the two dependent groupsbaseline registration and second registration in group 2 and also taking into account different numbers of regis- trations by each physician, Wilcoxon's signed-rank test was used.

The data analyses were performed using the SPSS 17.0. software.

\subsection{Ethical}

Approval was obtained from the local ethics committee in Blekinge as well as from all other participating countries. Informed consent was obtained from every participating physician.

\section{RESULTS}

Of the 77 physicians, 38 physicians representing all of the 18 PHCCs discontinued participation before the second registration (group 1). Thirty-nine participated fully in the audit process (group 2) representing 16 of the 18 PHCCs. Group 1 registered 812 consultations. Group 2, in which the 39 physicians completed participation, registered 1039 consultations in January 2008 and 895 consultations in January 2009.

Table 1 shows the respiratory tract diagnoses in group 1 and group 2 from the baseline audit registration and, regarding group 2, from the second registration. Table 2 shows the proportion of antibiotic prescribing. Table 3 shows the mean proportion and range of CRP near-patient tests, Strep-A near-patient tests and antibiotic prescriptions when the different numbers of consultation registration by the physicians were taken into account.

\subsection{Comparing Group 1 with Group 2}

\subsubsection{Consultation Level}

For all diagnoses in the baseline audit registration there was a significant difference in the overall use of CRP near-patient tests between physicians belonging to groups 1 and 2, 37\% vs 28\% (Chi-square $\mathrm{p}<0.001$ ). There was also a significant difference in the overall use of Strep-A near-patient tests, 31\% vs 20\% (Chi-square p $<0.001$ ), but not in the total number of antibiotic prescriptions, $44 \%$ vs $40 \%$ (Chi-square $\mathrm{p}=0.07$ ). When the Strep-A near-patient test was negative and the physician marked the diagnosis pharyngitis/tonsillitis, physicians in group 1 prescribed antibiotics to $45 \%$ as compared with $12 \%$ in group 2 (Chi-square 0.003 ).

\subsubsection{Aggregated Data on Physician Level}

When different numbers of consultation registrations by the physicians were taken into account in the baseline audit registration, the proportion of Strep-A near-patients tests in the group "diagnoses not recommended for treatment with antibiotics” was significantly higher in group 1 than in group 2 (Mann-Whitney U-test $\mathrm{p}=0.02$ ) (Table 3). 
Table 1. Proportion of diagnoses in percent noted by the physicians participating only at baseline (group 1) and physicians participating in both registrations (group 2).

\begin{tabular}{cccc}
\hline & \multicolumn{3}{c}{ Percent } \\
\cline { 2 - 4 } Number of consultations & Group 1 & Group 2 \\
\cline { 2 - 4 } & $\begin{array}{c}\text { Baseline registration } \\
(\mathrm{n}=812)\end{array}$ & $\begin{array}{c}\text { Baseline registration } \\
(\mathrm{n}=1039)\end{array}$ & $\begin{array}{c}\text { Second registration } \\
(\mathrm{n}=895)\end{array}$ \\
\hline Upper respiratory tract infection & 34 & 37 & 32 \\
Acute otitis media & 12 & 11 & 12 \\
Acute rhinosinusitis & 7 & 6 & 6 \\
Acute pharyngitis & 2 & 5 & 3 \\
Acute pharyngotonsillitis & 16 & 11 & 11 \\
Acute bronchitis & 10 & 12 & 10 \\
Pneumonia & 5 & 5 & 5 \\
Exacerbation of COPD & 1 & 2 & 2 \\
Influenza & 2 & 1 & 7 \\
Diagnosis not noted & 7 & 7 & 2 \\
\hline
\end{tabular}

Table 2. Proportion of antibiotic prescriptions for different diagnoses registered by the physicians participating only at baseline (group 1), and physicians participating in both registrations (group 2).

\begin{tabular}{cccc}
\hline & \multicolumn{3}{c}{ Proportion (Percent) } \\
\cline { 2 - 4 } & Group 1 & Group 2 \\
\cline { 2 - 4 } & Baseline registration & Baseline registration & Second registration \\
\hline Upper respiratory tract infection & $3 / 277(1)$ & $11 / 384(3)$ & $6 / 285(2)$ \\
Acute otitis media & $82 / 94(87)$ & $97 / 108(90)$ & $87 / 105(83)$ \\
Acute otitis media in patients $\geq 2$ years & $60 / 71(84)$ & $74 / 85(87)$ & $66 / 85(78)$ \\
Acute sinusitis & $48 / 53(91)$ & $53 / 62(85)$ & $49 / 58(85)$ \\
Acute pharyngitis & $6 / 19(32)$ & $4 / 50(8)$ & $2 / 24(8)$ \\
Acute tonsillitis & $121 / 131(92)$ & $109 / 117(93)$ & $89 / 95(94)$ \\
Acute bronchitis & $29 / 84(34)$ & $49 / 128(38)$ & $24 / 91(26)$ \\
Acute pneumonia & $33 / 36(92)$ & $45 / 47(96)$ & $43 / 45(96)$ \\
Acute exacerbation of COPD & $8 / 9(89)$ & $16 / 23(70)$ & $16 / 22(73)$ \\
\hline
\end{tabular}

When the physician marked the diagnosis pharyngitis/ tonsillitis, and the different numbers of consultation registration were taken into account, Strep-A near-patient tests were used in $83 \%$ by group 1 and in $61 \%$ by group 2 (Mann-Whitney U-test $\mathrm{p}=0.004)$. When the Strep-A near-patient test was positive and the different numbers of consultation registration were taken into account, the physician in both groups almost always treated the patient with antibiotics.

\subsection{Group 2 before and after the Intervention}

\subsubsection{Consultation Level}

After the intervention, the total use of Strep-A nearpatient tests among the physicians who completed both audit registrations decreased from $20 \%$ to $16 \%$ (Chisquare $\mathrm{p}=0.02$ ) and antibiotic prescriptions for "diagnosis not recommended for treatment with antibiotics" decreased from $27 \%$ to $22 \%$ (Chi-square $\mathrm{p}=0.03$ ).

\subsubsection{Aggregated Data on Physician Level}

After the intervention, there was a significant reduction in the overall use of CRP and Strep-A near-patient tests and in antibiotic prescription for the diagnoses classified as not recommended for treatment with antibiotics (Table 3). If the Centor critera (tonsillar exudates, swollen tender anterior cervical nodes, and history of fever $>38.5$ ) but cough was present [26] the proportion of Strep-A tests used decreased from $14 \%$ to $7 \%$ (Wilcoxon's signed-rank test $\mathrm{p}=0.003$ ). 
Table 3. Mean proportion of actions taken in conjunction with the consultation with the physician, taking different numbers of consultation registrations into account.

\begin{tabular}{|c|c|c|c|}
\hline \multirow{3}{*}{ Total number of physicians } & \multicolumn{3}{|c|}{ Mean percent (range) } \\
\hline & \multirow{2}{*}{$\begin{array}{c}\text { Group } 1 \\
\begin{array}{c}\text { Baseline registration } \\
(\mathrm{n}=38)\end{array}\end{array}$} & \multicolumn{2}{|c|}{ Group 2} \\
\hline & & $\begin{array}{l}\text { Baseline registration } \\
\qquad(\mathrm{n}=39)\end{array}$ & $\begin{array}{l}\text { Second registration } \\
\qquad(\mathrm{n}=39)\end{array}$ \\
\hline All diagnoses & $(n=812)$ & $(n=1039)$ & $(n=895)$ \\
\hline CRP & $38(0-100)$ & $35(0-91)$ & $30(0-100)^{2}$ \\
\hline Strep-A & $28(0-95)$ & $20(0-71)$ & $13(0-73)^{3}$ \\
\hline Antibiotic prescription & $44(11-100)$ & $38(0-87)$ & $35(0-67)$ \\
\hline $\begin{array}{l}\text { Diagnosis not recommended for treatment with } \\
\text { antibiotics }\end{array}$ & $(n=628)$ & $(n=843)$ & $(n=711)$ \\
\hline CRP & $41(0-100)$ & $36(0-100)$ & $31(0-100)$ \\
\hline Strep-A & $24(0-91)$ & $16(0-68)^{1}$ & $12(0-80)$ \\
\hline Antibiotic prescription & $28(0-100)$ & $25(0-80)$ & $21(0-62)^{4}$ \\
\hline $\begin{array}{l}\text { Diagnosis recommended for treatment with } \\
\text { antibiotics }\end{array}$ & $(n=184)$ & $(n=196)$ & $(n=184)$ \\
\hline CRP & $29(0-100)$ & $37(0-100)$ & $30(0-100)$ \\
\hline Strep-A & $42(0-100)$ & $29(0-100)$ & $18(0-100)$ \\
\hline Antibiotic prescription & $96(67-100)$ & $95(60-100)$ & $92(33-100)$ \\
\hline
\end{tabular}

${ }^{1}$ Mann-Whitney U-test for comparison between baseline in group I and baseline in group 2, p $=0.02$; ${ }^{2}$ Wilcoxon Signed rank test for comparisons between baseline and second registration post-intervention in Group 2, p $=0.005$; ${ }^{3}$ Wilcoxon Signed rank test for comparisons between baseline and second registration in Group 2, $\mathrm{p}=0.001$; ${ }^{4}$ Wilcoxon Signed rank test for comparisons between baseline and second registration in Group 2, $\mathrm{p}<0.05$.

\section{DISCUSSION}

The results show that physicians who only participated at baseline (group 1) prescribed more antibiotics for tonsillitis/pharyngitis when the Strep-A near-patient test was negative. The overall use of CRP near-patient tests and Strep-A near-patient tests was also higher in this group than among physicians who completed both audit registrations (group 2).

The APO method makes it possible to collect and analyse a great deal of information about a consultation in a simple way, and it is a useful tool for inducing and maintaining desirable changes in prescribing habits [27].

At the beginning of the study all physicians who agreed to participate received the same information about the study, and were informed that it was an educationally oriented study with two registration periods, one at the beginning of the study period and one a year later. We do not know whether or not the physicians actually registered all consultations for respiratory tract infections.

One strength of the study is that when we compared group 1 and group 2 we only used the data from the first registration period for those physicians who participated in both registrations (group 2). Another strength is that in one analysis we also took into account the fact that the number of registered consultations varied between the physicians, by aggregating data on physician level. Multilevel modelling was not applicable in this small study. Despite the fact that this registration method demanded little effort on the part of the physicians', nearly half of them chose not to take part in the second registration. One explanation might be differences in the interest in the topic. It may feel simpler to participate when you are already interested in a topic. This idea is supported by other behavioural studies [28]. Another reason might be the question of whether or not the physicians find it important to study their own habits. If there is an interest in the topic combined with an interest in studying one's own habits, we think the likelihood for full participation is greater.

To our knowledge, this is the first study of differences among physicians with "discontinued participation" and physicians with "complete participation" concerning antibiotic prescribing patterns and use of near-patient tests. One audit concerning diabetes care found a difference in blood pressure management but not in any other process parameter between "discontinued" and "complete" participation [23]. According to a previous study, physicians choosing to take part from the beginning in a registration study have different antibiotic prescribing habits than physicians choosing not to take part [18], and our study indicates that there also are different habits between those willing to complete an audit registration and those who were not.

This study shows that there were differences in management of RTIs between the two groups, and it is clear that the physicians who only participated at baseline 
were also less inclined to follow the guidelines. The short educationally oriented intervention also indicated that those who completed participation complied better with the recommendations after the intervention. For example, decreased use of Strep A were seen which might be a result of the intervention. However, this needs to be investigated further in a randomised controlled trial.

Strep-A near-patient tests can be helpful in finding S.p. in clinical work, but it is very important to have strict criteria for when they should be used. A previous Swedish study indicated just like ours that there is an overuse of near-patient tests [29]. If physicians use them improperly there is a risk of overuse of antibiotics since carriers of S.p. also will be diagnosed. The importance of monitoring the use of near-patient tests should be born in mind when introducing near-patient testing in new countries.

Since rational use of antibiotics is of major concern for minimizing antibiotic resistance, any intervention method that leads to less prescribing is of value. It is well known that the choice of whether or not to prescribe antibiotics is determined by the habits of the consulting physician [30]. Studies in continuing medical education (CME) have shown that when a topic is of relatively great interest to the physician there is an improvement, irrespective of CME or not, and when a topic is not of particular interest, CME in that topic is important [28]. If you are familiar with the guidelines and also have opportunities to discuss them, you comply with them. Review articles have also shown that CME activities were associated with improvements in physicians' knowledge [31] and that adding media such as the Internet or multiple educational techniques was more successful than using just one technique [32]. Possibly compulsory CME activities can be one way of dealing with the problem of non-adherence to guidelines.

\section{CONCLUSION}

These findings provide some evidence that those who do not like to participate in studies like the Happy Audit project are likely to behave in a way that is less evidencebased. This suggests that education and implementation activities should be supported by the employer and viewed upon as a never ending, iterative process in order to increase both participation and fulfilling of such processes. Perhaps a clear recommendation from the employer of the importance of taking part in projects such as Audit registrations would be valuable. In conclusion, this study showed that physicians, who were more inclined to complete audit participation, used near-patient tests and prescribed antibiotics more correctly, according to the national guidelines for respiratory tract infections, than physicians who discontinued the participation. To achieve a rational use of antibiotics, near-patient tests and prescription of antibiotics must be used according to guidelines.

\section{COMPETING INTERESTS}

The authors declare that they have no competing interests. No funding was received for this study.

\section{AUTHORS' CONTRIBUTIONS}

$\mathrm{KH}$ participated in the design of the study, acquisition of data, performed the statistical analysis and drafted the manuscript. AB has been involved in acquisition of data and revising the manuscript for important intellectual content. SM participated in the design of the study and has been involved in drafting the manuscript and revising it critically for important intellectual content. ELS participated in the design of the study, acquisition of data and have been involved in drafting the manuscript and revising it critically for important intellectual content.

\section{ACKNOWLEDGEMENTS}

The authors are grateful to all the physicians who took part in the Happy Audit project and to Ingvar Ovhed, MD PhD, the authors' colleague. We also want to thank Anna Lindgren for valuable statistical tutoring.

\section{REFERENCES}

[1] Grimsmo, A., Hagman, E, Faiko, E., Matthiessen, L. and Njalsson, T. (2001) Patients, diagnoses and processes in general practice in the Nordic countries. An attempt to make data from computerised medical records available for comparable statistics. Scandinavian Journal of Primary Health Care, 19, 76-82.

http://www.ncbi.nlm.nih.gov/entrez/query.fcgi?cmd=Retr ieve\&db=PubMed\&dopt=Citation \&list uids $=11482418$

[2] Tähepold, H., Maaroos, H.I., Kalda, R. and Van den Brink-Muinen, A. (2003) Structure and duration of consultations in Estonian family practice. Scandinavian Journal of Primary Health Care, 21, 167-170.

http://www.ncbi.nlm.nih.gov/entrez/query.fcgi?cmd=Retr ieve\&db=PubMed\&dopt=Citation\&list uids=14531509 http://dx.doi.org/10.1080/02813430310000708

[3] Andre, M., Vernby, A., Odenholt, I., Lundborg, C.S., Axelsson, I., Eriksson M., et al. (2008) Diagnosis-prescribing surveys in 2000, 2002 and 2005 in Swedish general practice: Consultations, diagnosis, diagnostics and treatment choices. Scandinavian Journal of Infectious Diseases, 40, 1-7.

http://www.ncbi.nlm.nih.gov/entrez/query.fcgi?cmd=Retr ieve\&db=PubMed \&dopt=Citation\&list_uids $=18609223$ http://dx.doi.org/10.1080/00365540801932439

[4] Consensus Development Statement (2000) Treatment of acute inflammation of the middle ear. Consensus Development Statement, Stockholm.

[5] Medical Product Agency (2001) Management of pharyngotonsillitis-Recommendations. Information från Läke- 
medelsverket, 12, 44-70.

[6] Medical Product Agency (2005) Pharmacological treatment of rhinosinusitis, recommendations. Information från läkemedelsverket, 16 7-13.

http://www.lakemedelsverket.se/malgrupp/Halso---sjukva rd/Behandlings--rekommendationer/Behandlingsrekomm endation---listan/Rinosinuit/

[7] Medical Product Agency (2010) Diagnosis, treatment and follow-up of acute media otitis. Läkemedelsverket Informerar, 21, 13-24.

http://www.lakemedelsverket.se/malgrupp/Halso---sjukva rd/Behandlings--rekommendationer/Behandlingsrekomm endation---listan/Otit-akut-mediaotit---AOM/

[8] Medical Product Agency (2012) Management of pharyngotonsillitics in open care-Background dokumentation. Läkemedelsverket Informerar, 6, 26-66.

http://www.lakemedelsverket.se/malgrupp/Halso---sjukva rd/Behandlings--rekommendationer/Behandlingsrekomm endation---listan/Faryngotonsilliter-i-oppen-vard/

[9] Lasseter, G.M., McNulty, C.A., Hobbs, F.D., Mant, D. and Little, P. (2009) In vitro evaluation of five rapid antigen detection tests for group A beta-haemolytic streptococcal sore throat infections. Family Practice, 26, 437444. http://www.ncbi.nlm.nih.gov/entrez/query.fcgi?cmd $=$ Retrieve\&db=PubMed\&dopt=Citation\&list_uids $=19748$ $\underline{913}$

http://dx.doi.org/10.1093/fampra/cmp054

[10] Medical Product Agency (2008) Pharmacological treatment of lower respiratory tract infections in outpatient care-Recommendations. Läkemdelsverkt Informerar, 19, 3. http://www.lakemedelsverket.se/Tpl/RecommendationsPa ge 7287.aspx

[11] Andre, M., Schwan, A. and Odenholt, I. (2004) The use of CRP tests in patients with respiratory tract infections in primary care in Sweden can be questioned. Scandinavian Journal of Infectious Diseases, 36, 192-197.

http://www.ncbi.nlm.nih.gov/entrez/query.fcgi?cmd=Retr ieve \&db=PubMed\&dopt=Citation\&list_uids $=15119364$ http://dx.doi.org/10.1080/00365540410019372

[12] Goossens, H., Ferech, M., Vander Stichele, R. and Elseviers, M. (2005) Outpatient antibiotic use in Europe and association with resistance: A cross-national database study. Lancet, 365, 579-587.

http://www.ncbi.nlm.nih.gov/entrez/query.fcgi?cmd=Retr ieve\&db=PubMed\&dopt=Citation\&list_uids=15708101

[13] Costelloe, C., Metcalfe, C., Lovering, A., Mant, D. and Hay, A.D. (2010) Effect of antibiotic prescribing in primary care on antimicrobial resistance in individual patients: Systematic review and meta-analysis. British Medical Journal (Clinical Research Ed.), 340, c2096. http://www.ncbi.nlm.nih.gov/entrez/query.fcgi?cmd=Retr ieve\&db=PubMed\&dopt=Citation\&list_uids=20483949 http://dx.doi.org/10.1136/bmj.c2096

[14] Bjerrum, L., Boada, A., Cots, J.M., Llor, C., Fores Garcia, D., Gahrn-Hansen, B., et al. (2004) Respiratory tract infections in general practice: Considerable differences in prescribing habits between general practitioners in Denmark and Spain. European Journal of Clinical Pharmacology, 60, 23-28.
http://www.ncbi.nlm.nih.gov/entrez/query.fcgi?cmd=Retr $\underline{\text { ieve } \& \mathrm{db}=\text { PubMed\&dopt=Citation\&list_uids }=14689127}$

[15] Hellman, J., Norman, C. and Olsson-Liljequist, B. (2010) Swedres-A report on Swedish Antibiotic Utilisation and Resistance in Human Medicine 2010, Swedish Institute for Communicable Disease Control, Stockholm. http://www.strama.se/dyn//,226,18,70.html

[16] McGavock, H. (1988) Some patterns of prescribing by urban general practitioners. British Medical Journal (Clinical Research Ed.), 296, 900-902.

http://www.ncbi.nlm.nih.gov/entrez/query.fcgi?cmd=Retr ieve\&db=PubMed\&dopt=Citation\&list_uids $=3129067$ http://dx.doi.org/10.1136/bmj.296.6626.900

[17] Gjelstad, S., Dalen, I. and Lindbaek, M. (2009) GPs' antibiotic prescription patterns for respiratory tract infections-Still room for improvement. Scandinavian Journal of Primary Health Care, 27, 208-215.

http://www.ncbi.nlm.nih.gov/entrez/query.fcgi?cmd=Retr ieve\&db=PubMed\&dopt=Citation\&list_uids=19929185 http://dx.doi.org/10.3109/02813430903438718

[18] Strandberg, E.L., Ovhed, I., Troein, M. and Hakansson, A. (2005) Influence of self-registration on audit participants and their non-participating colleagues. A retrospective study of medical records concerning prescription patterns. Scandinavian Journal of Primary Health Care, 23, 42-46. http://www.ncbi.nlm.nih.gov/entrez/query.fcgi?cmd=Retr ieve \&db=PubMed\&dopt=Citation\&list_uids $=16025873$ http://dx.doi.org/10.1080/02813430510018400

[19] Bjerrum, L.M., Reutskiy, A., Llor, C., Cotos, J.M., Caballero, L., Ovhed, I., Strandberg, E.L., Radzeviciene, R. and Gahrn-Hansen, B. (2010) Happy Audit report of the results-Respiratory tract infections in general practice. Happy Audit, Odense.

[20] Bjerrum, L., Munck, A., Gahrn-Hansen, B., Hansen, M.P., Jarboel, D., Llor, C., et al. (2010) Health alliance for prudent prescribing, yield and use of antimicrobial drugs in the treatment of respiratory tract infections (HAPPY AUDIT). BMC Family Practice, 11, 29.

http://www.ncbi.nlm.nih.gov/entrez/query.fcgi?cmd=Retr ieve\&db=PubMed\&dopt=Citation\&list_uids=20416034 http://dx.doi.org/10.1186/1471-2296-11-29

[21] Bjerrum, L., Munck, A., Gahrn-Hansen, B., Hansen, M.P., Jarbol, D.E., Cordoba, G., et al. (2011) Health Alliance for prudent antibiotic prescribing in patients with respiratory tract infections (HAPPY AUDIT) - Impact of a nonrandomised multifaceted intervention programme. BMC Family Practice, 12, 52.

http://www.ncbi.nlm.nih.gov/pubmed/21689406 http://dx.doi.org/10.1186/1471-2296-12-52

[22] Bentzen, N. (1993) Medical audit-The APO-method in general practice. Scandinavian Journal of Primary Health Care, 11, 13-18.

http://www.ncbi.nlm.nih.gov/entrez/query.fcgi?cmd=Retr ieve\&db=PubMed\&dopt $=$ Citation\&list_uids $=8493408$ http://dx.doi.org/10.3109/02813439308997643

[23] Hansen, C., Hansen, D., Kragstrup, J., Busch, O. and Munck, A. (2003) The role of the APO method in improving diabetes care in general practice: The results of a Danish prospective multipractice audit circle. Quality in 
Primary Care, 11, 225-232.

[24] Strandberg, E.L. (2008) Developing general practice: The role of the APO method. Department of Clinical Sciences, Malmö, General Practice/Family Medicine Malmö University Hospital, Lund University, Malmö.

[25] Munck, A.P., Hansen, D.G., Lindman, A., Ovhed, I., Forre, S. and Torsteinsson, J.B. (1998) A Nordic collaboration on medical audit. The APO method for quality development and continuous medical education (CME) in primary health care. Scandinavian Journal of Primary Health Care, 16, 2-6.

http://www.ncbi.nlm.nih.gov/pubmed/9612871 http://dx.doi.org/10.1080/028134398750003313

[26] Centor, R.M., Witherspoon, J.M., Dalton, H.P., Brody, C.E. and Link, K. (1981) The diagnosis of strep throat in adults in the emergency room. Medical Decision Making, 1, 239-246.

http://www.ncbi.nlm.nih.gov/entrez/query.fcgi?cmd=Retr ieve\&db=PubMed\&dopt=Citation\&list_uids=6763125 http://dx.doi.org/10.1177/0272989X8100100304

[27] Munck, A.P., Gahrn-Hansen, B., Sogaard, P. and Sogaard, J. (1999) Long-lasting improvement in general practitioners' prescribing of antibiotics by means of medical audit. Scandinavian Journal of Primary Health Care, 17, 185190.

http://www.ncbi.nlm.nih.gov/entrez/query.fcgi?cmd=Retr ieve\&db=PubMed\&dopt=Citation\&list_uids $=10555250$ http://dx.doi.org/10.1080/028134399750002629

[28] Sibley, J.C., Sackett, D.L., Neufeld, V., Gerrard, B., Rudnick, K.V. and Fraser, W. (1982) A randomized trial of continuing medical education. The New England Journal of Medicine, 306, 511-515.

http://www.ncbi.nlm.nih.gov/entrez/query.fcgi?cmd=Retr $\underline{\text { ieve } \& \mathrm{db}=\text { PubMed\&dopt }=\text { Citation \&list uids }=7057858}$
http://dx.doi.org/10.1056/NEJM198203043060904

[29] Neumark, T., Brudin, L. and Molstad, S. (2010) Use of rapid diagnostic tests and choice of antibiotics in respiratory tract infections in primary healthcare-A 6-y follow-up study. Scandinavian Journal of Infectious Diseases, 42, 90-96.

http://www.ncbi.nlm.nih.gov/pubmed/19902992 http://dx.doi.org/10.3109/00365540903352932

[30] Andre, M., Odenholt, I., Schwan, A., Axelsson, I., Eriksson, M., Hoffman, M., et al. (2002) Upper respiratory tract infections in general practice: Diagnosis, antibiotic prescribing, duration of symptoms and use of diagnostic tests. Scandinavian Journal of Infectious Diseases, 34, 880-886.

http://www.ncbi.nlm.nih.gov/entrez/query.fcgi?cmd=Retr ieve\&db=PubMed\&dopt=Citation\&list_uids=12587619 http://dx.doi.org/10.1080/0036554021000026952

[31] Bordage, G., Carlin, B. and Mazmanian, P.E. (2009) Continuing medical education effect on physician knowledge: Effectiveness of continuing medical education: American College of Chest Physicians Evidence-Based Educational Guidelines. Chest, 135, 29S-36S. http://www.ncbi.nlm.nih.gov/entrez/query.fcgi?cmd=Retr ieve\&db=PubMed\&dopt=Citation\&list_uids $=19265073$ http://dx.doi.org/10.1378/chest.08-2515

[32] Davis, D. and Galbraith, R. (2009) Continuing medical education effect on practice performance: Effectiveness of continuing medical education: American College of Chest Physicians Evidence-Based Educational Guidelines. Chest, 135, 42S-48S.

http://www.ncbi.nlm.nih.gov/entrez/query.fcgi?cmd=Retr ieve\&db=PubMed\&dopt=Citation\&list_uids $=19265075$ http://dx.doi.org/10.1378/chest.08-2517 